\title{
Education and Maternal Health in Pakistan: The Pathways of Influence
}

\section{Shandana Dar and Uzma Afzal ${ }^{* *}$}

\begin{abstract}
Although numerous studies have explored the relationship between education and women's health-seeking behavior, the role of education - and the pathway through which it affects health-seeking behavior - remains unclear. We use data from the Pakistan Demographic Health Survey for 2006/07 on women aged 1549 who had given birth at least once in the last three years to determine which socioeconomic factors affect maternal healthcare use, and how the effect of women's own education is transmitted to their health-seeking behavior. We implement two estimation techniques: (i) a two-step instrumental variable linear probability model, in which women's exposure to mass media is used as an instrumental variable for their health knowledge; and (ii) a community fixed effects model. The results of the analysis indicate that predisposing factors - such as women's level of education, their children's birth order, their spouse's level of education, type of occupation, and empowerment - are important determinants of maternal health-seeking behavior in Pakistan. The results also confirm the important role played by women's own health knowledge, independent of their education, on their maternal healthcare use.
\end{abstract}

Keywords: Maternal health, education, health knowledge, instrumental variable analysis, mass media exposure, Pakistan.

JEL classification: C26, I15, I29.

\section{Introduction}

The World Health Organization (WHO) defines maternal health as the "health of women during pregnancy, childbirth and postpartum period." While motherhood should be a positive and fulfilling experience, for far too many women, giving birth is associated with suffering, ill health, and even death (WHO, 2006).

Although women play a principal role in shaping society, they remain at alarmingly high risk of maternal morbidity and mortality. Every

\footnotetext{
* Lahore School of Economics, Pakistan.

** Assistant Professor and Research Fellow, Lahore School of Economics, Pakistan.
} 
life lost in pregnancy and childbirth has multiplicative effects, given that it is women who are responsible for bringing up children and managing household affairs (Tura \& Gebremariam, 2008). These spillovers of maternal health begin from the time a woman becomes pregnant. Decisions made during pregnancy, at the time of delivery, and post-delivery have lifelong implications for mother and child alike. Decreasing maternal mortality is, therefore, one of the most important global agendas of health.

WHO (2013) reports that the maternal mortality ratio (MMR) in Pakistan was 260 per 100,000 live births in 2010. Estimates show that, although Pakistan's MMR has declined by 47 percent since 1990, the country's performance lags behind others. The Government of Pakistan has made extensive efforts to decrease maternal mortality through a number of vertical and horizontal mother-and-child healthcare programs, such as the Family Planning and Primary Healthcare Program (Lady Health Workers Program) and National Maternal and Child Health Program. Although overall spending on health has increased, the share of health expenditure as a percentage of GDP remains low at 0.42 percent in 2014/15. Pakistan has made moderate progress in achieving some of the Millennium Development Goals, such as universal female health worker coverage by 2015, but the goal to reduce maternal mortality to 140 deaths per 100,000 births and child mortality to 52 deaths per 1,000 births will not be achieved by 2015 .

There is an extensive body of literature on the socioeconomic determinants of maternal health in Bangladesh, India, and Nepal, but a dearth of such studies on Pakistan. Moreover, the existing studies have limited application for Pakistan at large because they employ data from specific regions or provinces of the country. Most recognize the direct effect of some socioeconomic determinants on maternal health-seeking behavior (age, birth order, or previous fetal loss). However, determinants such as education can affect health-seeking behavior through multiple channels. Other branches of health literature, such as child health, have studied at length the pathway through which education affects the health-seeking behavior of an individual. Nevertheless, few studies underpin this causal mechanism in the literature on maternal health.

This paper is an extension of existing studies that identify key socioeconomic determinants of maternal healthcare utilization by women in developing countries such as Pakistan. Its twofold objective is to (i) determine which socioeconomic factors affect women's use of maternal healthcare services in Pakistan, and (ii) identify the pathway through which 
the effect of women's education is transmitted to their maternal healthseeking behavior.

We draw on data from the Pakistan Demographic Health Survey (PDHS) for 2006/07, which covers approximately 92,340 households. Carried out by the National Institute of Population Studies with the explicit goal of providing much-needed reliable information on maternal and neonatal health in Pakistan, the PDHS gives a comprehensive picture of marriage, fertility preferences, use of family planning methods, and maternal healthcare utilization. It is, therefore, well suited to our purposes. We use the instrumental variable (IV) technique to estimate the determinants of maternal health behavior; the choice of instrument for the endogenous variable is based on the literature. The results identify women's educational attainment and that of their spouses, women's health knowledge, and their children's birth order as important determinants of maternal health-seeking behavior in Pakistan.

The structure of the paper is as follows. Section 2 provides an overview of the literature on maternal health behavior. Section 3 describes the dataset used, and Section 4 outlines the conceptual framework and econometric methodology. Our empirical findings are presented in Section 5 , followed by a conclusion and policy recommendations in Section 6 .

\section{A Review of the Literature}

A vast body of theoretical and empirical literature examines the socioeconomic determinants of maternal health-seeking behavior among women in developing countries (see, for example, Elo, 1992; Bhatia \& Cleland, 1995; Celik \& Hotchkiss, 2000; Gyimah, Takyi, \& Addai, 2006; Mumtaz \& Salway, 2007; Sepehri, Sarma, Simpson, \& Moshiri, 2008; Amin, Shah, \& Becker, 2010; Singh, Rai, Alagarajan, \& Singh, 2012). Given the need to improve maternal health in Pakistan, however, there is a surprising dearth of empirical studies in this context. This study aims to fill this gap.

Among others, a mother's age is a well-established determinant of maternal health behavior. The use of antenatal care and assisted delivery is higher among older women, implying that maternal age serves as a proxy for women's accumulated knowledge (Elo, 1992). At the other end of the spectrum, some studies argue that the use of maternal healthcare is higher among adolescent women who are emotionally less mature and lack reproductive knowledge (see Amin et al., 2010; Singh et al., 2012). 
Numerous studies point to the positive effect of women's schooling on their maternal health-seeking behavior (see Elo, 1992; Celik \& Hotchkiss, 2000; Amin et al., 2010; Singh et al., 2012). An interesting observation is that education has a direct and indirect effect on outcome variables. While schooling increases women's health knowledge, the cognitive skills acquired at school increase their ability to assess and assimilate information, and increase their stock of health knowledge even after they leave school. Yet, despite the accepted importance of education for maternal health, most studies have failed to identify the underlying mechanism through which women's schooling affects their health-seeking behavior. Some exceptions are Elo (1992), Celik and Hotchkiss (2000), and LeVine, LeVine, Rowe, and Schnell-Anzola (2004), who argue that education transforms household dynamics and modifies women's beliefs such that educated women are better able to process knowledge. However, while Elo (1992) and Celik and Hotchkiss (2000) discuss the possible means through which women's education affects their health-seeking behavior, they do not empirically test any such mechanism.

The more recent literature on child health underpins the educationhealth nexus (see Thomas, Strauss, \& Henriques, 1991; Glewwe, 1999; Kovsted, Pörtner, \& Tarp, 2002; Webb \& Block, 2003; Afzal, 2013). The empirical evidence suggests that much of the education effect translates into health-seeking behavior through the health knowledge that women accumulate with the help of the literacy and numeracy skills they acquire at school.

However, Glewwe (1999), Kovsted et al. (2002), Webb and Block (2003), and Aslam and Kingdon (2012) suggest that, while health knowledge enables women to recognize the need for healthcare, the use of healthcare services helps women acquire additional health knowledge. Health knowledge may, therefore, be an endogenous variable per se if correlated with unobservable individual characteristics as well as with the outcome variable of interest. Studies have tackled this endogeneity issue by using the IV technique, where the most widely used instruments for health knowledge are mass media exposure, maternal education and the presence of close relatives.

To control for this endogeneity issue, we use women's exposure to mass media as an IV for their health knowledge, following the methodology of Glewwe (1999) and Aslam and Kingdon (2012). Glewwe uses household ownership of a radio or television and the availability of newspapers to represent mass media exposure, although the former does not necessarily mean that women have access to the content they convey. Aslam and 
Kingdon take this a step further and consider a woman exposed to mass media only if she reports watching television. Even so, this approach to capturing mass media exposure indicates neither the frequency with which women watch television nor the type of programs they view. For this study, we use the criterion "heard/watched a family planning program on radio or television in the last month" as an instrument to measure the type of programs women view.

Children's birth order is also a key factor in determining whether a woman seeks healthcare. One possible explanation for this is that a woman expecting her first child is more likely to be cautious and rely on medical assistance than women at a higher birth order. Those who have had more children tend to attach less importance to pregnancy, particularly if they have not experienced difficulties during previous pregnancies (Elo, 1992; Celik \& Hotchkiss, 2000). Similarly, women who have experienced fetal loss have a higher likelihood of being cautious and using maternal healthcare (Midhet, Becker, \& Berendes, 1998).

Prior studies recognize that the patriarchal nature of most Asian societies mean that women's position is multidimensional and intrahousehold decisions are complex. Male involvement in reproductive healthcare utilization is, therefore, increasingly recognized. Furuta and Salway (2006) establish that female autonomy is not restricted to control over household finances in the Asian context. They find that women's propensity for discussing family planning with their husbands has a significant effect on the uptake of maternal healthcare. The study captures the extent of women's empowerment using data on discussions between husband and wife concerning the place of delivery of the last child as a proxy.

The literature also stipulates that wealthier households use maternal healthcare services more frequently than less affluent households. Similarly, larger families limit the amount of resources available to each family member, reducing the affordability and use of maternal healthcare (see Shariff \& Singh, 2002; Mumtaz \& Salway, 2007; Singh et al., 2012). A more widely used measure of household wealth is a composite wealth index comprising the household's durable assets as well as characteristics.

Another important determinant of maternal healthcare at the individual level is geography, which includes community-level factors such as physical access to a hospital or pharmacy or the state of road infrastructure (see Elo, 1992; Celik \& Hotchkiss; 2000, Gyimah et al., 2006; Gage \& Calixte, 2006; Sepehri et al., 2008; Amin et al., 2010). After adjusting 
for individual-level factors, Gage and Calixte (2006) find that poor roads and lack of transportation significantly reduce the likelihood that a woman will receive antenatal care and make four or more antenatal care visits. The availability of a health center within $5 \mathrm{~km}$, however, significantly increases mothers' use of medical assistance.

To some extent, the literature has examined factors determining maternal health-seeking behavior in Pakistan (see, for instance, Midhet et al., 1998; Nisar \& White, 2003; Mumtaz \& Salway, 2007; Dasgupta, Mansuri, Sinha, \& Vishwanath, 2007; Ali, Bhatti, \& Kuroiwa, 2008; Agha \& Carton, 2011; Hou \& Ma, 2011). However, most of these studies draw on simplified assumptions and estimation techniques, which renders their results questionable. Moreover, their scope is limited because they include data from specific regions and provinces of Pakistan. While the recent literature on other countries might provide valuable insight into maternal health, it is important to account for local contexts when developing social policies.

Most studies on maternal health use only antenatal consultation as a dichotomous dependent variable, although WHO (2006) and Sepehri et al. (2008) argue that full antenatal care comprises tetanus toxoid injections and the frequency of visits to a healthcare facility. In addition, unlike prenatal care and safe delivery, the role of postnatal care as a pillar of safe motherhood is relatively untapped in the literature. Agha and Carton (2011) and Hou and Ma (2011) are two recent studies that employ postnatal care provided by a trained service provider as a component of maternal healthcare services in Pakistan.

The paucity of empirically sound studies on maternal health in Pakistan makes this paper an important contribution to the literature as it attempts to identify the partial effect through which women's health knowledge affects their maternal health-seeking behavior. Community fixed effects and IVs are implemented as separate specifications to control for the possible endogeneity of community-level factors such as infrastructure, access to roads, and the natural environment. Moreover, the analysis relies not only on the use of antenatal care, but also on the frequency, type of delivery, and use of postnatal care as dependent variables. Finally, the dataset used in this study is the PDHS for 2006/07: neither these outcome variables nor the PDHS - which provides a wealth of data - have been used in other studies on maternal health-seeking behavior in Pakistan. 


\section{Data and Summary Statistics}

The PDHS for 2006/07, a nationally representative, cross-sectional dataset, involves two-stage sampling. In the first stage, a total of 1,000 clusters were identified; in the second stage, 105 households were selected from each sampling point. The survey's purpose is to monitor the population and health situation in Pakistan and track its performance in meeting the Millennium Development Goals.

Unlike conventional demographic and health surveys, the PDHS was designed with the primary objective of obtaining data on maternal and neonatal health. It provides a comprehensive picture of marriage, fertility preferences, the use of family planning methods and maternal healthcare use. The data was collected from rural as well as urban areas across the four provinces, making it appropriate for a cross-country analysis. As we have already noted, in spite of the extensive information available, very few fertility studies on Pakistan have employed the PDHS 2006/07.

While the survey questionnaire is designed to gather wide-ranging information at both the household as well as individual level, our analysis is conducted at the individual level. The total sample comprises 10,023 women. The working sample includes married women aged 15-49 who gave birth at least once in the three years prior to the survey. ${ }^{1}$ The PDHS gives a broad range of information on each birth; to ensure this data is used accurately, we focus on the most recent births closest to the time of interview. This particular sample comprises 4,475 women, 65 percent of who are from rural areas and 34 percent from urban areas.

Table 1 shows that only 39 percent of Pakistani women visited a medical facility for antenatal care at least three times during their last pregnancy. Just over half (51 percent) received at least two tetanus toxoid injections; 38 percent delivered their child at a health facility or under a health professional's care, and only 24 percent utilized postnatal care. Moreover, there is a pronounced difference in the proportion of women who utilized maternal health services in rural and urban areas: only 29 percent of women in rural areas made at least three antenatal visits during pregnancy as opposed to 56 percent in urban areas.

\footnotetext{
${ }^{1}$ We restrict the sample to at least one birth in the three years prior to the survey, given that some women might not respond accurately in connection with births before this interval (see Celik \& Hotchkiss, 2000).
} 
Table 1: Descriptive statistics: mean and standard deviation for overall Pakistan data

\begin{tabular}{|c|c|c|c|}
\hline Variable & Mean & SD & Observ. \\
\hline \multicolumn{4}{|l|}{ Outcome variables } \\
\hline \multicolumn{4}{|l|}{ Antenatal care } \\
\hline At least three antenatal visits during pregnancy $(=1)$ & 0.39 & 0.49 & 4,418 \\
\hline $\begin{array}{l}\text { At least two tetanus toxoid injections during } \\
\text { pregnancy }(=1)\end{array}$ & 0.51 & 0.50 & 4,406 \\
\hline Safe delivery $(=1)$ & 0.38 & 0.49 & 4,460 \\
\hline Postnatal care $(=1)$ & 0.24 & 0.43 & 4,475 \\
\hline \multicolumn{4}{|l|}{ Individual characteristics } \\
\hline \multicolumn{4}{|l|}{ Age } \\
\hline$<25(=1)$ & 0.28 & 0.45 & 4,475 \\
\hline $25-34(=1)$ & 0.52 & 0.50 & 4,475 \\
\hline $35-49(=1)$ & 0.20 & 0.40 & 4,475 \\
\hline \multicolumn{4}{|l|}{ Education } \\
\hline None or less than primary $(=1)$ & 0.71 & 0.45 & 4,475 \\
\hline Primary but below middle $(=1)$ & 0.09 & 0.29 & 4,475 \\
\hline Middle but below secondary $(=1)$ & 0.07 & 0.25 & 4,475 \\
\hline Secondary and above $(=1)$ & 0.13 & 0.34 & 4,475 \\
\hline Literacy skills $(=1)$ & 0.34 & 0.47 & 4,475 \\
\hline Health knowledge $(=1)$ & 0.48 & 0.50 & 4,461 \\
\hline \multicolumn{4}{|l|}{ Mass media exposure } \\
\hline $\begin{array}{l}\text { Heard family planning message on radio or TV in } \\
\text { the last month }(=1)\end{array}$ & 0.37 & 0.48 & 4,474 \\
\hline Working woman $(=1)$ & 0.27 & 0.44 & 4,471 \\
\hline \multicolumn{4}{|l|}{ Child's birth order } \\
\hline $1(=1)$ & 0.19 & 0.39 & 4,475 \\
\hline 2 to $3(=1)$ & 0.35 & 0.48 & 4,475 \\
\hline 4 to $6(=1)$ & 0.31 & 0.46 & 4,475 \\
\hline $7+(=1)$ & 0.15 & 0.36 & 4,475 \\
\hline Previous fetal loss or stillbirth $(=1)$ & 0.22 & 0.45 & 4,475 \\
\hline Previous fetal loss or stillbirth * working woman $(=1)$ & 0.08 & 0.26 & 4,471 \\
\hline Planned pregnancy $(=1)$ & 0.74 & 0.44 & 4,475 \\
\hline \multicolumn{4}{|l|}{ Husband's education } \\
\hline None or less than primary $(=1)$ & 0.41 & 0.49 & 4,475 \\
\hline Primary but below middle $(=1)$ & 0.11 & 0.31 & 4,475 \\
\hline Middle but below secondary $(=1)$ & 0.15 & 0.36 & 4,475 \\
\hline Secondary and above $(=1)$ & 0.32 & 0.47 & 4,475 \\
\hline Husband has skilled employment $(=1)$ & 0.53 & 0.50 & 4,474 \\
\hline Discussed place of delivery with spouse $(=1)$ & 0.44 & 0.50 & 4,475 \\
\hline
\end{tabular}




\begin{tabular}{lccc}
\hline Variable & Mean & SD & Observ. \\
\hline Husband is a blood relation (=1) & 0.52 & 0.50 & 4,471 \\
Wife of household head (=1) & 0.51 & 0.50 & 4,474 \\
& & & \\
Household characteristics & & & \\
Household wealth (index) & & & \\
Low & -1.15 & 0.33 & 840 \\
Medium-low & -0.45 & 0.15 & 839 \\
Medium & -0.01 & 0.11 & 840 \\
Medium-high & 0.39 & 0.14 & 840 \\
High & 1.21 & 0.66 & 839 \\
Number of household members & 9.96 & 5.57 & 4,475 \\
& & & \\
Community-level characteristics & & & \\
Place of residence & & & \\
Region & & & \\
Urban (=1) & 0.35 & 0.48 & 4,475 \\
Rural (=1) & 0.65 & 0.48 & 4,475 \\
Province & & & \\
Punjab (=1) & 0.40 & 0.49 & 4,475 \\
Sindh (=1) & 0.29 & 0.45 & 4,475 \\
KP (=1) & 0.20 & 0.40 & 4,475 \\
Balochistan (=1) & 0.11 & 0.32 & 4,475 \\
\hline
\end{tabular}

Note: (=1) represents dummy variable; the mean is a proportion of this variable.

Source: Authors' calculations based on PDHS 2006/07.

The descriptive statistics also show that more than 70 percent of women across Pakistan are uneducated or have less than primary education; only 13 percent reported having received higher education. Of these, 81 percent were from rural areas and 52 percent from urban areas. To assess women's literacy skills, this study uses the results of a literacy test conducted as part of the PDHS to gauge reading ability. Only 24 percent of rural women claimed some level of literacy as against 53 percent in urban areas.

Moreover, the data show that urban women in Pakistan are more likely to discuss matters with their husbands and are, therefore, more empowered than their rural counterparts. Additionally, we use a series of questions asked as part of the PDHS to measure women's awareness of the risks and problems associated with pregnancy. The data show that less than 50 percent of women are aware of such problems. Interestingly, there is no pronounced difference between rural and urban women in terms of health knowledge. 
Next, we construct a wealth index comprising household assets and housing conditions using principal component analysis. This allows us to rank individuals on the basis of their "household scores and divide them in different quintiles, each representing 20 percent of the score between 1 (poorest) and 5 (wealthiest)" (Singh et al., 2012). ${ }^{2}$ Separate t-tests are conducted to identify any differences in the individual and household characteristics of women residing in rural and urban Pakistan. The results (available on request) indicate that there is no significant difference in the characteristics of rural and urban women.

\section{Conceptual Framework and Estimation Strategy}

According to Anderson's (1968) behavioral model, a household's medical care practices are based on the interplay of its predisposing, enabling, and need factors (see Figure 1). Health-seeking behavior is, therefore, "a sequential and conditional function of an individual's predisposition to use health services, their perceived need to use them and their ability to obtain these services" (Amin et al., 2010, p. 11). The actual use of healthcare is triggered by need during the prenatal and postnatal stages of pregnancy. However, in the absence of such data, we explore the extent to which predisposing and enabling factors affect maternal health behavior.

To identify the socioeconomic determinants of maternal healthcare behavior among currently married women in Pakistan, we begin with a simple model:

$$
M H B=\beta_{0}+\alpha I+\varphi H+\gamma C+\varepsilon
$$

where MHB is women's maternal health-seeking behavior, I represents a vector comprising their individual characteristics, $\mathrm{H}$ is a vector of household characteristics, and $\mathrm{C}$ represents community characteristics.

\footnotetext{
${ }^{2}$ The wealth index is constructed using the following variables: material used to construct roof, walls and flooring; type of sanitation facilities and cooking fuel available; availability of electricity; ownership status of house; ownership of consumer durables (cooler, air conditioner, refrigerator, bicycle, motorcycle, scooter, car, truck, telephone, washing machine, water pump, sewing machine, computer, bed, chairs, cabinets, sofa, camera).
} 
Figure 1: Conceptual framework for determinants of health-seeking behavior in Pakistan

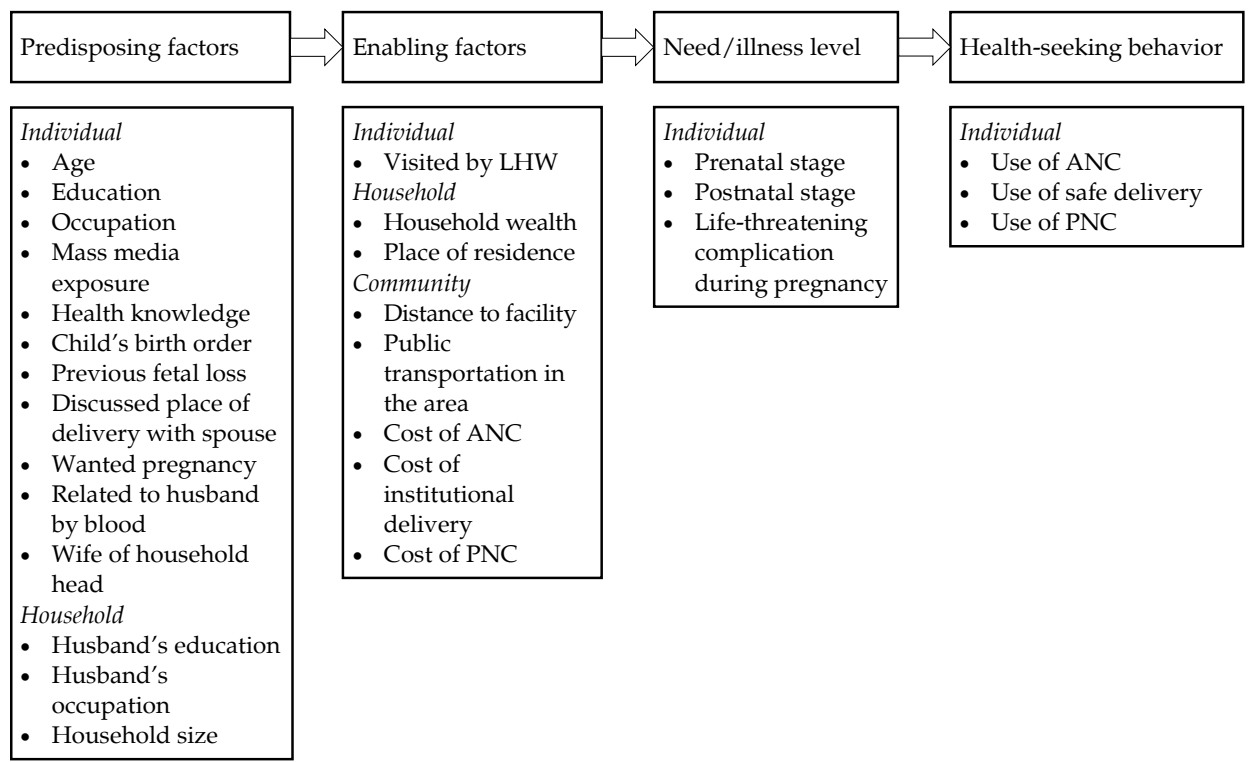

Source: Amin, Shah, and Becker (2010).

\subsection{Description of Variables}

MHB is the variable of interest, reflecting women's healthcare use during pregnancy. Under WHO's (2006) recommendations, the following components, when combined, constitute complete maternal healthcare (Table 2). Antenatal care is not complete unless women are protected from unhygienic practices and other risks via tetanus toxoid injections. The number of visits to a healthcare facility is also an important factor: by frequently visiting health facilities, women come into direct contact with health professionals, with whom they develop a rapport. Together, these components constitute complete antenatal care. 
Table 2: List of dependent variables under MHB

\begin{tabular}{ll}
\hline Antenatal care & $\begin{array}{l}\text { Dummy variable }=1 \text { if woman has had at least three } \\
\text { antenatal visits; }=0 \text { otherwise. }\end{array}$ \\
& $\begin{array}{l}\text { Dummy variable }=1 \text { if woman has had at least two } \\
\text { tetanus toxoid injections; }=0 \text { otherwise. }\end{array}$ \\
Safe delivery & $\begin{array}{l}\text { Dummy variable }=1 \text { if delivery took place at a health } \\
\text { facility or at home by a doctor, nurse, lady health visitor, } \\
\text { auxiliary nurse, midwife, or other health professional; }=0 \\
\text { otherwise. }\end{array}$ \\
Postnatal care & $\begin{array}{l}\text { Dummy variable }=1 \text { if trained postnatal care was } \\
\text { obtained within } 42 \text { days of delivery; }=0 \text { otherwise. }\end{array}$ \\
\hline
\end{tabular}

\subsection{Endogeneity and Other Specification Issues}

Simple OLS estimation can result in biased estimates due to the feedback effect between certain individual characteristics and women's decision to seek maternal healthcare, resulting in an endogeneity problem. Unobservable community-level characteristics can also result in biased estimates.

\subsubsection{Women's Education and Maternal Healthcare Behavior}

While the positive association between women's education and their health-seeking behavior is largely undisputed, the mechanism through which this relationship works has not been studied in detail. Apart from the theoretical evidence, the problem is largely methodological.

Equation (1) assumes that women's education has a direct effect on their maternal health-seeking behavior. Schooling can influence women's health behavior by improving their ability to process information efficiently through the cognitive skills (literacy or numeracy) they learn at school. Conversely, the acquisition of health knowledge is not restricted to the period women are enrolled in school - the literacy and numeracy skills they acquire during this time can increase women's health knowledge even after leaving school (Thomas et al., 1991; Glewwe, 1999; Aslam \& Kingdon, 2012). This study captures both the direct and indirect effect by adding the following pathways of education as control variables:

- $\quad$ Education $\rightarrow$ literacy skills $\rightarrow$ maternal health behavior

- Education $\rightarrow$ literacy skills $\rightarrow$ health knowledge $\rightarrow$ maternal health behavior 
Literacy skills acquired at school enable women to assess and assimilate information successfully, and increase their health knowledge, which affects their health-seeking behavior (Glewwe, 1999). Maternal health knowledge is itself a potentially endogenous variable. While health knowledge helps identify the need to avail maternal health services, women who seek healthcare are likely to have greater health knowledge. Thus, the causality runs in both directions. To control for endogeneity, we use the IV technique where exposure to media is the instrument.

For women, an important source of information and health knowledge is their exposure to mass media (see Thomas et al., 1991; Glewwe, 1999; LeVine et al., 2004; Aslam \& Kingdon, 2012). We use information received through family planning messages broadcasted on radio or television in the last month as an instrument for health knowledge. The PDHS provides information on households' ownership of a radio or television, along with the type of health message delivered to women through these media. This study considers a woman having been exposed to mass media only if she reports having "heard a family planning message on radio or television last month."

We assume that this particular measure of mass media increases awareness among women, improves their health knowledge, and affects their health-seeking behavior. ${ }^{3}$ The instrument is informative because listening to a family planning message on the radio or television is unlikely to affect women's health-seeking behavior through any other mechanism but increased health knowledge. Moreover, it is highly improbable that women would listen to family planning messages on the radio or television because they had received maternal healthcare. This makes mass media exposure a valid instrument

\subsubsection{Omitted Variable Problem}

Short-run fluctuations in a household's resources, represented by its income or income per capita, are an important determinant of the ability and willingness to pay for healthcare services. Following the pattern of the USAID-sponsored demographic and health surveys, the PDHS 2006/07 does not have any information on household income, but does provide extensive data on ownership of household assets.

\footnotetext{
${ }^{3}$ The instrument is well established in the literature. While there is a strong correlation between owning a television and listening to a health message (see footnote 4), the correlation is weaker for owning a radio. This strengthens the case for listening to a health message resulting in increased health knowledge as opposed to merely owning a television.
} 
We develop a wealth index based on household ownership of durable assets. It is important to note that ownership of a radio or television is not included in the index. This is because the data show there is a strong correlation between households that own either a radio or television and women who have heard a family planning message on radio or television. 4 Including these consumer durables in the wealth index would thus decrease the IV's explanatory power.

We also use the level of education attained by women's spouses and their occupation as independent variables. These covariates closely reflect spouses' earnings and control for the relative socioeconomic status of a household.

Although community-level covariates such as the quality of local health infrastructure cannot be included in the model (due to data unavailability), they are important determinants of healthcare use and can result in biased coefficients unless controlled for. Elo (1992) notes that bettereducated women might belong to a particular community that has more schools, for instance. This can confound the relationship between women's education and their health-seeking behavior. To eliminate the omitted variable bias caused by community characteristics, we estimate a cluster fixed effects model. Fixed effects at a smaller level eliminate all the characteristics common to women in a single cluster, thus avoiding omitted variable bias.

\subsection{Estimation Strategy}

Given that the predicted probabilities of the outcome variables are bound between 0 and 1, we use a probit model to assess the impact of socioeconomic factors on the uptake of maternal health services. Since health knowledge is potentially endogenous, the model is estimated using the IV technique. The first stage of the two-stage least squares (2SLS) model involves a probit model to predict the probability of health knowledge. The second stage is an ordinary least squares (OLS) model.

Stage 1 is represented by the following equation:

$$
\begin{aligned}
& \text { Health knowledge } \text { kn }_{i}=\psi+\Sigma \alpha I+\Sigma \varphi H+\Sigma \gamma C+ \\
& \text { Amass media exposure }_{i}+\varepsilon
\end{aligned}
$$

\footnotetext{
${ }^{4}$ Ninety percent of women from households that owned a television reported listening to a family planning message in the last month (PDHS 2006/07). Forty percent of women from households that owned a radio reported listening to a family planning message in the last month (PDHS 2006/07).
} 
Stage 2 is represented by the following equation:

$$
M H B_{i}=\beta+\Sigma \alpha \mathrm{I}+\varphi_{i} \text { health } \hat{k} n o w l e d g e_{i}+\Sigma \varphi \mathrm{H}+\Sigma \gamma \mathrm{C}+\varepsilon
$$

Vector I captures individual-level characteristics; the household's environment is captured by vector $H$. C represents community characteristics, health knowledge (measured by women's awareness of the risks and complications of pregnancy) is the endogenous variable, and mass media exposure is the IV. This selection of variables is drawn from the choice of variables in the literature and the corresponding data available in the PDHS 2006/07.

In addition, we estimate the following fixed effects logit model:

$$
\mathrm{MHB}=\beta+\Sigma \alpha \mathrm{I}+\Sigma \varphi \mathrm{H}+\theta_{c}+\varepsilon
$$

Equation (4) represents fixed effects at the cluster level (the primary sampling unit). This model controls for the distance to a health facility and the quality of local health infrastructure as well as other unobservable heterogeneity within sampling units, which cannot be controlled for by the covariates included in the analysis. The variable $\theta_{c}$ captures the unobserved heterogeneity constant across communities, that is, all unobserved factors, constant among sampling units, that affect maternal health-seeking behavior. The IV technique is also implemented in the fixed effects logit model and the predicted values of health knowledge used in the estimation.

\section{Results and Empirical Findings}

The econometric specification we follow uses all the possible variables given in Figure 1 that could affect women's maternal healthseeking behavior in Pakistan.

\subsection{First-Stage Results}

In the first stage of the two-step linear probability model (LPM), the endogenous covariate is regressed on the IV using the probit estimation technique (see Table A1 in the Appendix). Note that this first stage remains the same for all the dependent variables mentioned in the previous section.

To establish that mass media exposure is an informative instrument, we carry out an Angrist-Prischke F-test. The first-stage F-statistic value is 25.18, which is greater than 10, allowing us to reject the null hypothesis (i.e., that the IV has no explanatory power). Moreover, the significant coefficient 
of the IV in the first-stage regression indicates that mass media exposure strongly influences women's health knowledge. It is important to note that the programs disseminating information on family planning are public service programs with nationwide outreach. Along with private channels, they are also broadcasted on national channels, irrespective of the type of area or village to which the target audience might belong. This makes mass media exposure an exogenous variable.

The second stage, based on the OLS method, uses the predicted endogenous covariate, health knowledge, obtained from the first stage as an explanatory variable, along with other individual and household-level characteristics to identify which factors determine women's maternal healthcare use. The estimations are conducted using data for Pakistan overall, controlling for regional and provincial differences among the three provinces of Punjab, Sindh, and Khyber Pakhtunkhwa (KP). Further, to control for community-specific factors such as the quality of local health infrastructure, we employ cluster fixed effects. In all cases, we control for heteroskedasticity of unknown form by implementing robust standard errors at the cluster level.

The explanatory variables are classified as individual characteristics, household characteristics, and community characteristics. Women's individual characteristics, their household characteristics, and community characteristics are regressed separately on four binary dependent variables: (i) made at least three antenatal visits to a healthcare facility (yes $=1$, no $=0$ ), (ii) received at least two tetanus toxoid inoculations (yes $=1$, no $=0$ ), (iii) had a safe delivery (yes $=1$, no $=0$ ), and (iv) received postnatal care (yes $=1$, no $=0$ ).

\subsection{Second-Stage Results}

The results for the second stage of the IV probit model are discussed below. Table 3 reports the estimated parameters of the data for Pakistan overall for each outcome variable. The model also addresses the endogeneity problem.

Women's own characteristics include their age categorized into age cohorts. Column 1 suggests that women aged 35-49 have more maternal experience, but also undergo a riskier pregnancy and, therefore, have a higher probability of receiving antenatal care than women under the age of 25 . Similarly, women aged 35-49 have a greater probability of receiving at least two tetanus inoculations during pregnancy, safe delivery care, and postnatal 
care compared to women under 25 , given their older age and the higher risks associated with it. This effect reflects the findings of Elo (1992) who establishes that maternal healthcare use is higher among older women in Peru.

The coefficients for different categories of women's educational attainment show that women with middle and higher education are more likely to visit a healthcare facility seeking antenatal care at least three times during pregnancy compared to uneducated women. Interestingly, women who have received a formal education, but not completed middle school, also have a greater probability of making at least three antenatal visits. These results remain consistent for other aspects of maternal health-seeking behavior, such as tetanus toxoid inoculations, safe delivery, and postnatal care. This implies that all levels of education have a significantly positive effect on women's maternal health-seeking behavior (see Elo, 1992; Amin et al., 2010; Singh et al., 2012).

Table 3: LPM results for women's maternal healthcare use behavior

\begin{tabular}{|c|c|c|c|c|}
\hline \multirow[b]{2}{*}{ Explanatory variable } & \multicolumn{2}{|c|}{ Antenatal care } & \multirow{2}{*}{$\begin{array}{c}\begin{array}{c}\text { Safe } \\
\text { delivery }\end{array} \\
(3)\end{array}$} & \multirow{2}{*}{$\begin{array}{c}\begin{array}{c}\text { Postnatal } \\
\text { care }\end{array} \\
\text { (4) }\end{array}$} \\
\hline & (1) & (2) & & \\
\hline \multicolumn{5}{|l|}{ Individual char. } \\
\hline \multicolumn{5}{|l|}{ Age (years) } \\
\hline \multicolumn{5}{|l|}{$<25$ (ref.) } \\
\hline $25-34$ & $\begin{array}{l}0.026 \\
(0.019)\end{array}$ & $\begin{array}{l}-0.013 \\
(0.020)\end{array}$ & $\begin{array}{l}0.027 \\
(0.019)\end{array}$ & $\begin{array}{l}0.025 \\
(0.017)\end{array}$ \\
\hline $35-49$ & $\begin{array}{l}0.102^{* * *} \\
(0.027)\end{array}$ & $\begin{array}{l}0.074^{* * *} \\
(0.0292)\end{array}$ & $\begin{array}{l}0.114^{* * *} \\
(0.025)\end{array}$ & $\begin{array}{l}0.058^{* *} \\
(0.021)\end{array}$ \\
\hline \multicolumn{5}{|l|}{ Education } \\
\hline \multicolumn{5}{|l|}{$\begin{array}{l}\text { None or less than primary } \\
\text { (ref.) }\end{array}$} \\
\hline Primary but below middle & $\begin{array}{l}0.133^{* * *} \\
(0.028)\end{array}$ & $\begin{array}{l}0.176^{* * *} \\
(0.028)\end{array}$ & $\begin{array}{l}0.114^{* * *} \\
(0.027)\end{array}$ & $\begin{array}{l}0.065^{* * *} \\
(0.024)\end{array}$ \\
\hline $\begin{array}{l}\text { Middle but below } \\
\text { secondary }\end{array}$ & $\begin{array}{l}0.184^{* * *} \\
(0.030)\end{array}$ & $\begin{array}{l}0.199^{* * *} \\
(0.029)\end{array}$ & $\begin{array}{l}0.165^{* * *} \\
(0.031)\end{array}$ & $\begin{array}{l}0.109^{* * *} \\
(0.029)\end{array}$ \\
\hline Secondary and above & $\begin{array}{l}0.194^{* * *} \\
(0.029)\end{array}$ & $\begin{array}{l}0.153^{* * *} \\
(0.029)\end{array}$ & $\begin{array}{l}0.243^{* * *} \\
(0.028)\end{array}$ & $\begin{array}{l}0.174^{* * *} \\
(0.028)\end{array}$ \\
\hline Health knowledge a & $\begin{array}{l}1.254^{* * *} \\
(0.175)\end{array}$ & $\begin{array}{l}1.487^{* * *} \\
(0.188)\end{array}$ & $\begin{array}{l}0.522^{* * *} \\
(0.176)\end{array}$ & $\begin{array}{l}0.483^{* * *} \\
(0.161)\end{array}$ \\
\hline Working woman & $\begin{array}{l}-0.192^{* * *} \\
(0.022)\end{array}$ & $\begin{array}{l}-0.230^{* * * *} \\
(0.033)\end{array}$ & $\begin{array}{l}-0.116^{* * *} \\
(0.030)\end{array}$ & $\begin{array}{l}-0.095^{* * *} \\
(0.027)\end{array}$ \\
\hline $\begin{array}{l}\text { Child's birth order } \\
1 \text { (reference) }\end{array}$ & & & & \\
\hline
\end{tabular}




\begin{tabular}{|c|c|c|c|c|}
\hline \multirow[b]{2}{*}{ Explanatory variable } & \multicolumn{2}{|c|}{ Antenatal care } & \multirow{2}{*}{$\begin{array}{c}\begin{array}{c}\text { Safe } \\
\text { delivery }\end{array} \\
(3)\end{array}$} & \multirow{2}{*}{$\begin{array}{c}\begin{array}{c}\text { Postnatal } \\
\text { care }\end{array} \\
(4) \\
\end{array}$} \\
\hline & $(\mathbf{1})$ & $(2)$ & & \\
\hline \multirow[t]{2}{*}{2 to 3} & $-0.140^{* * *}$ & $-0.089^{* * *}$ & $-0.092^{* * *}$ & $-0.068^{* * *}$ \\
\hline & $(0.022)$ & $(0.022)$ & $(0.022)$ & $(0.020)$ \\
\hline \multirow[t]{2}{*}{4 to 6} & $-0.181^{* * *}$ & $-0.141^{* * *}$ & $-0.160^{* * *}$ & $-0.101^{* * *}$ \\
\hline & $(0.027)$ & $(0.028)$ & $(0.027)$ & $(0.024)$ \\
\hline \multirow[t]{2}{*}{$7+$} & $-0.278^{* * *}$ & $-0.249^{* * *}$ & $-0.185^{* * *}$ & $-0.133^{* * *}$ \\
\hline & $(0.036)$ & $(0.038)$ & $(0.037)$ & $(0.031)$ \\
\hline \multirow[t]{2}{*}{ Previous fetal loss or stillbirth } & $-0.102^{* * *}$ & $-0.142^{* * *}$ & -0.036 & -0.031 \\
\hline & $(0.026)$ & $(0.028)$ & $(0.027)$ & $(0.0251)$ \\
\hline \multirow{2}{*}{$\begin{array}{l}\text { Previous fetal loss or stillbirth } \\
\text { * working woman }\end{array}$} & $0.110^{* * *}$ & $0.065^{*}$ & $0.062^{*}$ & 0.019 \\
\hline & $(0.034)$ & $(0.041)$ & $(0.036)$ & $(0.032)$ \\
\hline \multirow[t]{2}{*}{ Wanted pregnancy } & 0.026 & $0.108^{* * *}$ & $0.040^{* *}$ & $0.055^{* * *}$ \\
\hline & $(0.021)$ & $(0.022)$ & $(0.021)$ & $(0.019)$ \\
\hline \multicolumn{5}{|l|}{ Husband's education } \\
\hline \multicolumn{5}{|l|}{$\begin{array}{l}\text { None or less than primary } \\
\text { (ref.) }\end{array}$} \\
\hline \multirow{2}{*}{ Primary but below middle } & -0.020 & -0.002 & 0.035 & 0.008 \\
\hline & $(0.024)$ & $(0.027)$ & $(0.024)$ & $(0.020)$ \\
\hline \multirow{2}{*}{$\begin{array}{l}\text { Middle but below } \\
\text { secondary }\end{array}$} & $0.046^{* *}$ & $0.057^{* *}$ & $0.038^{*}$ & 0.017 \\
\hline & $(0.023)$ & $(0.024)$ & $(0.022)$ & $(0.019)$ \\
\hline \multirow[t]{2}{*}{ Secondary and above } & $0.080^{* * *}$ & $0.077^{* * *}$ & $0.084^{* * *}$ & $0.077^{* * *}$ \\
\hline & $(0.020)$ & $(0.022)$ & $(0.020)$ & $(0.017)$ \\
\hline \multirow{2}{*}{$\begin{array}{l}\text { Husband has skilled } \\
\text { employment }\end{array}$} & $0.073^{* * *}$ & $0.044^{* *}$ & 0.003 & 0.021 \\
\hline & $(0.016)$ & $(0.018)$ & $(0.016)$ & $(0.014)$ \\
\hline \multirow{2}{*}{$\begin{array}{l}\text { Discussed place of delivery } \\
\text { with spouse }\end{array}$} & $0.060^{* *}$ & -0.017 & $0.119^{* * *}$ & $0.100^{* * *}$ \\
\hline & $(0.024)$ & $(0.026)$ & $(0.023)$ & $(0.021)$ \\
\hline \multirow[t]{2}{*}{ Husband is a blood relation } & $-0.053^{* * *}$ & -0.021 & -0.015 & -0.001 \\
\hline & $(0.015)$ & $(0.016)$ & $(0.014)$ & $(0.013)$ \\
\hline \multirow[t]{2}{*}{ Wife of household head } & $-0.035^{* *}$ & $-0.063^{* * *}$ & $-0.045^{* * *}$ & $-0.038^{* *}$ \\
\hline & $(0.017)$ & $(0.018)$ & $(0.017)$ & $(0.015)$ \\
\hline \multicolumn{5}{|l|}{ Household char. } \\
\hline \multirow[t]{2}{*}{ Household wealth (index) } & $0.043^{* * *}$ & 0.015 & $0.055^{* * *}$ & $0.037^{* * *}$ \\
\hline & $(0.009)$ & $(0.011)$ & $(0.010)$ & $(0.008)$ \\
\hline \multirow{2}{*}{$\begin{array}{l}\text { Number of household } \\
\text { members }\end{array}$} & -0.003 & -0.002 & -0.003 & -0.002 \\
\hline & $(0.002)$ & $(0.002)$ & $(0.002)$ & $(0.001)$ \\
\hline \multicolumn{5}{|l|}{ Community char. } \\
\hline \multicolumn{5}{|l|}{ Place of residence } \\
\hline \multicolumn{5}{|l|}{ Region } \\
\hline \multicolumn{5}{|l|}{ Urban (ref.) } \\
\hline Rural & $-0.081^{* * *}$ & $-0.034^{*}$ & $-0.105^{* * *}$ & $-0.080^{* * *}$ \\
\hline & $(0.019)$ & $(0.021)$ & $(0.021)$ & $(0.018)$ \\
\hline
\end{tabular}




\begin{tabular}{lllcl}
\hline & \multicolumn{2}{c}{ Antenatal care } & $\begin{array}{c}\text { Safe } \\
\text { delivery }\end{array}$ & $\begin{array}{c}\text { Postnatal } \\
\text { care }\end{array}$ \\
\cline { 2 - 5 } Explanatory variable & \multicolumn{1}{c}{$\mathbf{( 1 )}$} & \multicolumn{1}{c}{$\mathbf{( 2 )}$} & $\mathbf{( 3 )}$ & \multicolumn{1}{c}{$\mathbf{( 4 )}$} \\
\hline $\begin{array}{l}\text { Province } \\
\quad \text { Punjab (ref.) }\end{array}$ & & & & \\
$\quad$ Sindh & $-0.242^{* * *}$ & $-0.425^{* * *}$ & -0.022 & -0.017 \\
& $(0.049)$ & $(0.053)$ & $(0.051)$ & $(0.046)$ \\
KP & -0.019 & -0.012 & $0.047^{*}$ & -0.032 \\
& $(0.020)$ & $(0.026)$ & $(0.025)$ & $(0.019)$ \\
Constant & -0.007 & 0.030 & $0.190^{* * *}$ & 0.033 \\
& & & & \\
Number of observations & 4,133 & 4,125 & 4,172 & 4,186 \\
R-squared & 0.241 & 0.148 & 0.228 & 0.200 \\
\hline
\end{tabular}

Notes: ${ }^{*} \mathrm{p}<0.10,{ }^{* *} \mathrm{p}<0.05,{ }^{* * *} \mathrm{p}<0.01$. Robust standard errors at cluster level are given in parentheses below estimates.

Col. $1=$ min. three antenatal visits to health facility, col. 2 = received at least two tetanus toxoid injections, col. 3 = gave birth at health facility/by trained health service providers, col. $4=$ received trained postnatal care.

$\mathrm{a}=$ These are the predicted values of the health knowledge variable, obtained from the first stage of the IV probit model.

Source: Authors' calculations.

As mentioned in Section 4, women's education has an indirect effect on their maternal health-seeking behavior. Formal schooling enables women to assess and assimilate information more efficiently, which increases their health knowledge and thus affects the outcome variable. Health knowledge itself is, therefore, an important explanatory variable of health-seeking behavior.

By controlling for education, this study intends to isolate the impact of women's health knowledge on their health-seeking behavior. The positive and statistically significant coefficient of the health knowledge variable for all outcome variables supports this hypothesis, implying that women who are more aware of the issues and complications associated with pregnancy have a higher probability of seeking maternal healthcare (see columns 1-4 in Table 3). It is interesting to note that health knowledge has a more pronounced effect on complete antenatal care use than safe delivery and postnatal care.

The literature has established that women's employment status is associated with their empowerment and better healthcare-seeking behavior. Contrary to other studies, our results show that working women have a smaller probability of seeking antenatal care than women who are not working. This could be due to the former's financial status and nature. Work 
status may be picking up the effect of other socioeconomic characteristics of working women, for example, the combined effect of the household's financial standing, the nature of the woman's job, and the extent to which she is involved in intra-household decision making.

Table 1 shows that approximately 27 percent of women in the total sample are working, 79.5 percent of who are illiterate. Such low levels of education translate into lower earnings for these women. Moreover, of all the women who are working, 38 percent belong to the least wealthy households and only 7 percent belong to the wealthiest households (see Table A2). These statistics show that most working women fall within the lower income strata of the sample. Table A3 reiterates this by showing that, of the 27 percent of women who are working, only 14 percent have a skilled job while 86 percent work as low-paid, unskilled workers. The estimations, therefore, pick up the effect of working women with lower earnings who belong to poor households and cannot afford to seek healthcare.

In accord with the literature (see Elo, 1992; Celik \& Hotchkiss, 2000), the negative coefficients for children's birth order show that women expecting their first child have a greater probability of paying at least three visits to seek antenatal care compared to those at a higher birth order. Interestingly, this effect increases for all components of maternal healthcare as birth order increases. This suggests that women with more children rely on their experience and health knowledge from previous births, and may have less time and resources available to use maternal care for subsequent pregnancies.

Contrary to other findings on maternal health-seeking behavior, our results indicate that women who have experienced a fetal loss or stillbirth have less likelihood of seeking antenatal care, tetanus inoculations, and postnatal care compared to women with no maternal history. Given the unexpected sign of the result, we investigate the interaction of the variable with women's working status. The estimated parameters reported in column 3 show that whether a woman has a history of fetal loss or stillbirth does not have any effect on her probability of seeking safe delivery care.

However, when this variable interacts with the working women variable, the coefficient becomes positive and statistically significant for antenatal visits, tetanus inoculations, and safe delivery. The interaction term is constructed to gauge the impact of maternal history along with the household's socioeconomic status on the outcome variables. These results indicate that the likelihood of a woman visiting a health facility to seek antenatal care at least three times during pregnancy, of receiving tetanus 
inoculations, and of utilizing safe delivery care is higher if she is a working woman and has experienced fetal loss or stillbirth, keeping all other factors constant.

The literature suggests that women going through a planned pregnancy are more cautious and tend to attach greater importance to the child expected. The results for the variable planned pregnancy support the literature: it has a positive and significant effect on tetanus inoculations and use of safe delivery and postnatal care by women. This implies that a woman facing a planned pregnancy is more cautious and, therefore, has a higher probability of receiving maternal healthcare compared to a woman going through an unexpected pregnancy (see Ahmed \& Mosley, 2002; Sepehri et al., 2008).

The level of education attained by a woman's husband is hypothesized to reflect the household's economic wellbeing as it translates into higher earnings. At the same time, the husband's education reflects his perceptions and preferences with respect to modern medicine. The coefficient of the spouse's primary education is statistically insignificant for all the outcome variables, indicating that primary education alone is not enough to ensure higher earnings or modified attitudes toward maternal healthcare. However, women whose spouses have completed at least middle or higher schooling are more likely to seek maternal healthcare than women with illiterate spouses. These results are consistent with the literature, which argues that a higher level of spousal education translates into greater household income and increases women's probability of seeking maternal healthcare.

Another proxy for household economic wellbeing is whether a woman's spouse has skilled employment. The effect of this variable is also consistent with the literature: it shows that the probability of seeking antenatal care and receiving tetanus inoculations and postnatal care is higher for women whose spouses have skilled employment compared to those whose spouses have unskilled jobs. However, our results indicate that skilled employment in this context has no effect on women's likelihood of receiving safe delivery and postnatal care.

This study uses spousal discussion of the place of delivery as a proxy for women's involvement in the decision-making process. A woman's ability to make important decisions and influence her personal environment emerges as a strong determinant of maternal health behavior in the literature (see Furuta \& Salway, 2006; Mumtaz \& Salway, 2007; Hou \& Ma, 2011). In Pakistan, however, where family structures are usually complex and most 
women live in a joint family system, a woman's ability to make independent decisions is not an adequate measure of her autonomy. The variable spousal discussion is, therefore, a viable proxy for women's involvement in the decision-making process.

Our results show spousal discussion has a positive and significant effect on the likelihood of making at least three antenatal visits and seeking safe delivery and postnatal care. This implies that women who discuss such decisions with their spouse have a higher probability of seeking maternal healthcare, after controlling for all other individual and household characteristics (see Furuta \& Salway, 2006). Conversely, spousal discussion concerning the place of delivery does not influence women's decision to get at least two tetanus inoculations.

We also include the variable "wife of household head" to see if this has any effect on women's health-seeking behavior. Contrary to expectations, a woman who is the household head's wife has less probability of visiting a healthcare facility at least three times during pregnancy. The effect of this variable remains the same for tetanus inoculations, safe delivery, and postnatal care. Consanguineous marriages are very common in Pakistan and 52 percent of women in the working sample are married to their cousins. However, as the results in Table 4 show, controlling for other factors, consanguinity does not influence any outcome variable.

Household wealth and the number of household members are included in the model to capture household wellbeing. A wealth index comprising household conditions and ownership of durable assets is created using principal component analysis. The coefficient shows that, ceteris paribus, women from wealthier households have a greater probability of receiving maternal healthcare (see, for instance, Celik \& Hotchkiss, 2000; Shariff \& Singh, 2002; McTavish, Moore, Harper, \& Lynch, 2010).

The coefficients for the number of household members in relation to making at least three antenatal visits and safe delivery care are negative, implying that being part of a larger household has a strong adverse impact on women's antenatal care and safe delivery care utilization. This finding is in accord with the literature, which suggests that women from larger households have fewer resources at their disposal and are subject to more congestion and thinly stretched scarce resources compared to women in smaller households (see Shariff \& Singh, 2002; Mumtaz \& Salway, 2007; Singh et al., 2012). 
However, the size of a household does not influence the probability of a woman receiving tetanus inoculations. This is because, unlike other maternal health-seeking practices, tetanus inoculations do not necessarily involve mobility or incur any cost. Women visited by lady health workers are more likely to receive tetanus inoculations than those who are not. Unfortunately, there is not enough data in the PDHS to investigate behavioral differences in maternal health seeking caused by services delivered by lady health workers.

The results in Table 3 show that women living in rural areas are less likely to receive maternal healthcare than their urban counterparts. This is not surprising: urban areas have greater access to healthcare facilities than rural areas. However, there is no significant difference between rural and urban women's probability of receiving at least two tetanus inoculations. An interaction term is created for each variable that is statistically different between rural and urban areas (e.g., planned pregnancy) with the rural dummy variable. The effect of these interaction terms is insignificant for all the dependent variables and is not, therefore, included in the analysis.

At the provincial level, women in Sindh have a smaller probability of receiving complete antenatal care than women in Punjab. Fewer women in KP use safe delivery care compared to women in Punjab, after controlling for all other factors. Interestingly, there is no significant variation between women in Punjab and KP in terms of receiving complete antenatal and postnatal care.

\subsection{Community Fixed Effects}

The socioeconomic conditions of an area, cultural factors, and community-specific characteristics - such as the distance to the nearest health facility, the availability of public transport, and the quality of local health infrastructure - also affect the variable of interest and outcome variable. However, based on the availability of factors in the PDHS, these characteristics cannot be included in the analysis.

There is growing evidence in the literature that community-specific characteristics, such as the number of schools in a community, may affect the level of education attained by women as well as by their spouses. This is either because better-educated men and women belong to regions with better socioeconomic conditions or because educated people are more likely to migrate to areas with better economic opportunities.

To address this issue of omitted variable bias and isolate the impact

of education, we employ community fixed effects at the cluster level in a 
separate regression analysis involving the IV technique as well. On average, there are about 10 to 15 households in a primary sampling unit. Households within a primary sampling unit are located in the same vicinity so that observable and unobservable characteristics can be taken into account in the fixed effects model.

Table 4 provides fixed effects estimates at the cluster level for women's maternal health-seeking behavior. For all the dependent variables, the effect of all levels of women's education generally remains significant. However, there is a substantial decline in coefficient size, indicating that cluster-specific characteristics affect women's education in the IV probit model. In terms of the effect of the husband's education on women's maternal health-seeking behavior, the effect of all levels of education, except secondary and higher education, become insignificant once communityspecific characteristics are controlled for.

The fixed effects model also indicates that, prior to controlling for cluster-specific characteristics, the coefficient of health knowledge is attenuated. Table 4 shows that, while the effect of women's health knowledge on their maternal health-seeking behavior remains significant, the magnitude of this influence has declined.

Table 4 also shows that, once we control for heterogeneity within a sampling unit, there is no difference between the maternal health-seeking behavior of older and younger women, except in using safe delivery care. Similarly, women's maternal history does not influence their maternal healthcare use. The probability of women seeking safe delivery care is not affected by whether their pregnancy is planned or mistimed. This implies that the effect of planned pregnancy on women's use of safe delivery care is indeed confounded by area-specific characteristics. Once these characteristics are controlled for, women are inclined to seek maternal healthcare services irrespective of whether their pregnancy is planned or unplanned, due to the risks associated with childbirth.

Another key result of the fixed effects model is that the heterogeneity within sampling units seems to have the largest confounding effect on tetanus inoculations received by pregnant women in Pakistan. The results of cluster fixed effects show that women's age, primary schooling or employment status, previous fetal loss or stillbirth, and spouse's employment status do not influence their probability of receiving tetanus inoculations. 
Table 4: Cluster fixed effects for women's maternal healthcare use behavior

\begin{tabular}{|c|c|c|c|c|}
\hline \multirow[b]{2}{*}{ Explanatory variable } & \multicolumn{2}{|c|}{ Antenatal care } & \multirow{2}{*}{$\begin{array}{c}\begin{array}{c}\text { Safe } \\
\text { delivery }\end{array} \\
(3)\end{array}$} & \multirow{2}{*}{$\begin{array}{c}\begin{array}{c}\text { Postnatal } \\
\text { care }\end{array} \\
(4)\end{array}$} \\
\hline & (1) & (2) & & \\
\hline \multicolumn{5}{|l|}{ Individual char. } \\
\hline \multicolumn{5}{|l|}{ Age (years) } \\
\hline \multicolumn{5}{|l|}{$<25$ (ref.) } \\
\hline $25-34$ & $\begin{array}{l}0.00897 \\
(0.0279)\end{array}$ & $\begin{array}{l}-0.0110 \\
(0.0308)\end{array}$ & $\begin{array}{l}0.00725 \\
(0.0232)\end{array}$ & $\begin{array}{l}0.0144 \\
(0.0207)\end{array}$ \\
\hline $35-49$ & $\begin{array}{l}0.0521 \\
(0.0376)\end{array}$ & $\begin{array}{l}0.0167 \\
(0.0413)\end{array}$ & $\begin{array}{l}0.0779^{* *} \\
(0.0313)\end{array}$ & $\begin{array}{l}0.0363 \\
(0.0281)\end{array}$ \\
\hline \multicolumn{5}{|l|}{ Education } \\
\hline \multicolumn{5}{|l|}{ None or less than primary (ref.) } \\
\hline Primary but below middle & $\begin{array}{l}0.0920^{* * *} \\
(0.0357)\end{array}$ & $\begin{array}{l}0.0639 \\
(0.0395)\end{array}$ & $\begin{array}{l}0.0802^{* * *} \\
(0.0296)\end{array}$ & $\begin{array}{l}0.0464^{*} \\
(0.0265)\end{array}$ \\
\hline Middle but below secondary & $\begin{array}{l}0.0952^{* *} \\
(0.0407)\end{array}$ & $\begin{array}{l}0.104^{* *} \\
(0.0450)\end{array}$ & $\begin{array}{l}0.144^{* * *} \\
(0.0340)\end{array}$ & $\begin{array}{l}0.0802^{* * *} \\
(0.0304)\end{array}$ \\
\hline Secondary and above & $\begin{array}{l}0.0794^{*} \\
(0.0417)\end{array}$ & $\begin{array}{l}0.0800^{*} \\
(0.0453)\end{array}$ & $\begin{array}{l}0.163^{* * * *} \\
(0.0341)\end{array}$ & $\begin{array}{l}0.103^{* * *} \\
(0.0304)\end{array}$ \\
\hline Health knowledge & $\begin{array}{l}0.812^{* * *} \\
(0.257)\end{array}$ & $\begin{array}{l}0.942^{* * *} \\
(0.287)\end{array}$ & $\begin{array}{l}0.388^{*} \\
(0.212)\end{array}$ & $\begin{array}{l}0.378^{* *} \\
(0.189)\end{array}$ \\
\hline Working woman & $\begin{array}{l}-0.0639^{* *} \\
(0.0292)\end{array}$ & $\begin{array}{l}-0.0518 \\
(0.0317)\end{array}$ & $\begin{array}{l}-0.0663^{* * *} \\
(0.0238)\end{array}$ & $\begin{array}{l}-0.0630^{* * *} \\
(0.0213)\end{array}$ \\
\hline \multicolumn{5}{|l|}{$\begin{array}{l}\text { Child's birth order } \\
1 \text { (reference) }\end{array}$} \\
\hline 2 to 3 & $\begin{array}{l}-0.104^{* * *} \\
(0.0276)\end{array}$ & $\begin{array}{l}-0.0700^{* *} \\
(0.0304)\end{array}$ & $\begin{array}{l}-0.0736^{* * *} \\
(0.0229)\end{array}$ & $\begin{array}{l}-0.0602^{* * *} \\
(0.0205)\end{array}$ \\
\hline 4 to 6 & $\begin{array}{l}-0.166^{* * *} \\
(0.0348)\end{array}$ & $\begin{array}{l}-0.139^{* * *} \\
(0.0387)\end{array}$ & $\begin{array}{l}-0.156^{* * *} \\
(0.0291)\end{array}$ & $\begin{array}{l}-0.0941^{* * *} \\
(0.0260)\end{array}$ \\
\hline $7+$ & $\begin{array}{l}-0.218^{* * *} \\
(0.0454)\end{array}$ & $\begin{array}{l}-0.194^{* * *} \\
(0.0500)\end{array}$ & $\begin{array}{l}-0.138^{* * *} \\
(0.0378)\end{array}$ & $\begin{array}{l}-0.0998^{* * *} \\
(0.0337)\end{array}$ \\
\hline Previous fetal loss or stillbirth & $\begin{array}{l}-0.0379 \\
(0.0313)\end{array}$ & $\begin{array}{l}-0.0428 \\
(0.0345)\end{array}$ & $\begin{array}{l}-0.0116 \\
(0.0262)\end{array}$ & $\begin{array}{l}-0.0105 \\
(0.0235)\end{array}$ \\
\hline \multirow{2}{*}{$\begin{array}{l}\text { Previous fetal loss or stillbirth * working } \\
\text { woman } \\
\text { Wanted pregnancy }\end{array}$} & $\begin{array}{l}0.0748 \\
(0.0504)\end{array}$ & $\begin{array}{l}0.00330 \\
(0.0557)\end{array}$ & $\begin{array}{l}0.0517 \\
(0.0418)\end{array}$ & $\begin{array}{l}-0.00291 \\
(0.0375)\end{array}$ \\
\hline & $\begin{array}{l}-0.0160 \\
(0.0240)\end{array}$ & $\begin{array}{l}0.0696^{*} \\
(0.0271)\end{array}$ & $\begin{array}{l}0.0303 \\
(0.0202)\end{array}$ & $\begin{array}{l}0.0421^{* *} \\
(0.0179)\end{array}$ \\
\hline \multicolumn{4}{|l|}{ Husband's education } & \\
\hline Primary but below middle & $\begin{array}{l}-0.0577^{*} \\
(0.0333)\end{array}$ & $\begin{array}{l}-0.0258 \\
(0.0362)\end{array}$ & $\begin{array}{l}0.00177 \\
(0.0274)\end{array}$ & $\begin{array}{l}-0.00683 \\
(0.0246)\end{array}$ \\
\hline Middle but below secondary & $\begin{array}{l}0.0263 \\
(0.0311)\end{array}$ & $\begin{array}{l}0.0208 \\
(0.0350)\end{array}$ & $\begin{array}{l}0.0214 \\
(0.0261)\end{array}$ & $\begin{array}{l}0.0104 \\
(0.0233)\end{array}$ \\
\hline Secondary and above & $0.0650^{* *}$ & $0.0609^{* *}$ & $0.0791^{* * *}$ & $0.0929^{* * *}$ \\
\hline
\end{tabular}




\begin{tabular}{lllll}
\hline & \multicolumn{2}{c}{ Antenatal care } & $\begin{array}{c}\text { Safe } \\
\text { delivery }\end{array}$ & $\begin{array}{c}\text { Postnatal } \\
\text { care }\end{array}$ \\
\cline { 2 - 5 } Explanatory variable & \multicolumn{1}{c}{$(\mathbf{1})$} & \multicolumn{1}{c}{$\mathbf{( 2 )}$} & \multicolumn{1}{c}{$\mathbf{( 3 )}$} & \multicolumn{1}{c}{$\mathbf{( 4 )}$} \\
\hline \multirow{3}{*}{ Husband has skilled employment } & $(0.0274)$ & $(0.0303)$ & $(0.0228)$ & $(0.0204)$ \\
& $0.0390^{*}$ & 0.00171 & -0.0179 & 0.00329 \\
Discussed place of delivery with spouse & $(0.0221)$ & $(0.0245)$ & $(0.0182)$ & $(0.0163)$ \\
& $0.0944^{* *}$ & 0.0147 & $0.121^{* * *}$ & $0.108^{* * *}$ \\
Husband is a blood relation & $(0.0281)$ & $(0.0312)$ & $(0.0229)$ & $(0.0203)$ \\
Wife of household head & -0.0116 & -0.0242 & -0.0149 & -0.0197 \\
& $(0.0189)$ & $(0.0209)$ & $(0.0158)$ & $(0.0141)$ \\
Household char. & -0.00425 & -0.0125 & $-0.0416^{* *}$ & $-0.0333^{* *}$ \\
Household wealth (index) & $(0.0226)$ & $(0.0248)$ & $(0.0187)$ & $(0.0167)$ \\
& & & & \\
Number of household members & $0.0314^{* *}$ & 0.0171 & $0.0328^{* * *}$ & $0.0 .235^{* *}$ \\
& $(0.0135)$ & $(0.0150)$ & $(0.0113)$ & $(0.00998)$ \\
Number of observations & -0.00108 & -0.00357 & -0.00164 & -0.00192 \\
Adjusted R-squared & $(0.00215)$ & $(0.00238)$ & $(0.00179)$ & $(0.00161)$ \\
\hline
\end{tabular}

Notes: ${ }^{*} \mathrm{p}<0.10,{ }^{* *} \mathrm{p}<0.05,{ }^{* * *} \mathrm{p}<0.01$. Robust standard errors at cluster level are given in parentheses below estimates.

Col. $1=$ min. three antenatal visits to health facility, col. $2=$ received at least two tetanus toxoid injections, col. 3 = gave birth at health facility/by trained health service providers, col. 4 = received trained postnatal care.

Source: Authors' calculations.

\subsection{Additional Robustness Checks}

In order to verify the results obtained from the cross-sectional and fixed effects models for overall Pakistan data, we conduct a series of robustness checks. An IV probit model for the two-stage LPM with district fixed effects is applied to verify the findings of the cluster fixed effects model. The results of both are consistent with the primary models. Additional robustness checks include separate regressions for the provinces of Punjab, Sindh, and KP, and separate regressions for rural and urban areas. ${ }^{5}$

\section{Conclusion}

This study has attempted to identify the socioeconomic determinants of women's maternal health-seeking behavior in Pakistan, using the IV approach. Our results show that the level of education attained by a women and her spouse, her health knowledge, and her children's birth order are particularly important in determining whether she will seek maternal

${ }^{5}$ All these results are available on request. 
healthcare. The results of both the LPM as well as the fixed effects model confirm that formal schooling significantly influences women's maternal health-seeking behavior.

These effects of education are not, however, uniform across different levels of women's education, the net effect being highest for women who have completed secondary or higher education. Interestingly, we find that women with any level of formal schooling (even up to primary school) are more likely to seek maternal healthcare, thus reiterating the importance of education. On the other hand, women whose spouses have been educated up to the middle or higher level are more likely to seek healthcare than those whose husbands are less educated. This implies that a lower level of education among men is not sufficient to transform their attitudes toward seeking formal healthcare for their spouses.

An important finding is that health knowledge has a partial, albeit strong, effect on women's health-seeking behavior even after controlling for education. This implies that, while formal education can directly enhance women's health knowledge and enable them to access and process knowledge, other sources of information on health beyond those taught in school - such as radio, television, newspapers, and other instruments of mass media - can also effectively enhance their health knowledge.

The results also confirm that health knowledge can be acquired at any stage in life. Information on maternal healthcare broadcasted to the public particularly women of childbearing age - through mass media public service programs can help increase women's awareness of maternal healthcare as well as their desire to learn how to better handle maternity. This, in turn, encourages them to actively seek assistance from healthcare centers.

Moreover, according to our data, working women belong to less affluent households where their participation in the workforce may not be a personal decision reflecting their empowerment as much as a means of survival. This implies that, in a society characterized by complex family structures, women's empowerment is reflected better by their involvement in decision-making. Our results for spousal discussion of the place of delivery support this argument.

Overall, education increases women's knowledge, capabilities, and self-confidence, all of which are also empowering. In turn, women's increased self-awareness modifies the traditional balance of power in family structures and helps women assume greater responsibility for their healthseeking behavior. 


\section{References}

Afzal, U. (2013). What matters in child health: An instrumental variable analysis. Child Indicators Research, 6(4), 673-693.

Agha, S., \& Carton, T. W. (2011). Determinants of institutional delivery in rural Jhang, Pakistan. International Journal for Equity in Health, 10(31), 1-12.

Ahmed, S., \& Mosley, W. H. (2002). Simultaneity in the use of maternalchild healthcare and contraceptives: Evidence from developing countries. Demography, 39(1), 75-93.

Ali, M., Bhatti, M. A., \& Kuroiwa, C. (2008). Challenges in access to and utilization of reproductive healthcare in Pakistan. Journal of Ayub Medical College Abbottabad, 20(4), 3-7.

Amin, R., Shah, N. M., \& Becker, S. (2010). Socioeconomic factors differentiating maternal and child health-seeking behavior in rural Bangladesh: A cross-sectional analysis. International Journal for Equity in Health, 9(9), 1-11.

Anderson, R. M. (1968). Behavioral model of families' use of health services (Research Series No. 25). Chicago, IL: University of Chicago, Center of Health Administration Studies.

Andersen, R. M. (1995). Revisiting the behavioral model and access to medical care: Does it matter? Journal of Health and Social Behavior, 36(1), 1-10.

Anwar, M., Green, J., \& Norris, P. (2012). Health-seeking behavior in Pakistan: A narrative review of the existing literature. Public Health, 126(6), 507-517.

Aslam, M., \& Kingdon, G. G. (2012). Parental education and child health: Understanding the pathways of impact in Pakistan. World Development, 40(10), 2014-2032.

Becker, S., Fonseca-Becker, F., \& Schenck-Yglesias, C. (2006). Husbands' and wives' reports of women's decision-making power in western Guatemala and their effects on preventive health behaviors. Social Science and Medicine, 62(9), 2313-2326. 
Bhatia, J. C., \& Cleland, J. (1995). Determinants of maternal care in a region of South India. Health Transition Review, 5, 127-142.

Bloom, S. S., Wypij, D., \& Das Gupta, M. (2001). Dimensions of women's autonomy and the influence on maternal healthcare utilization in a north Indian city. Demography, 38(1), 67-78.

Celik, Y., \& Hotchkiss, D. R. (2000). The socioeconomic determinants of maternal healthcare utilization in Turkey. Social Science and Medicine, 50(12), 1797-1806.

Chauhan, A. (2012). Antenatal care among currently married women in Rajasthan, India. Asian Pacific Journal of Tropical Disease, 2(2), 617-623.

Das Gupta, M., Mansuri, G., Sinha, N., \& Vishwanath, T. (2007, March). Overcoming gender-based constraints to utilization of maternal and child health services in Pakistan: The role of the doorstep delivery system. Paper presented at the Annual Meeting of the Population Association of America, New York, NY.

Elo, I. T. (1992). Utilization of maternal healthcare services in Peru: The role of women's education. Health Transition Review, 2(1), 49-69.

Furuta, M., \& Salway, S. (2006). Women's position within the household as a determinant of maternal healthcare use in Nepal. International Family Planning Perspectives, 32(1), 17-27.

Gage, A. J., \& Calixte, M. G. (2006). Effects of the physical accessibility of maternal health services on their use in rural Haiti. Population Studies, 60(3), 271-288.

Glewwe, P. (1999). Why does mother's schooling raise child health in developing countries? Evidence from Morocco. Journal of Human Resources, 34(1), 124-159.

Gyimah, S. O., Takyi, B. K., \& Addai, I. (2006). Challenges to the reproductive-health needs of African women: On religion and maternal health utilization in Ghana. Social Science and Medicine, 62(12), 2930-2944.

Hassan, H., Jokhio, A. H., Winter, H., \& MacArthur, C. (2012). Safe delivery and newborn care practices in Sindh, Pakistan: A community-based investigation of mothers and health workers. Midwifery, 28(4), 466-471. 
Hou, X., \& Ma, N. (2011). Empowering women: The effect of women's decisionmaking power on reproductive health services uptake: Evidence from Pakistan (Policy Research Working Paper No. 5543). Washington, DC: World Bank.

Khan, A. (1999). Mobility of women and access to health family planning services in Pakistan. Reproductive Health Matters, 7(14), 39-48.

Kovsted, J., Pörtner, C. C., \& Tarp, F. (2002). Child health and mortality: Does health knowledge matter. Journal of African Economies, 11(4), 542-560.

LeVine, R. A., LeVine, S. E., Rowe, M. L., \& Schnell-Anzola, B. (2004). Maternal literacy and health behavior: A Nepalese case study. Social Science and Medicine, 58(4), 863-877.

McAlister, C., \& Baskett, T. F. (2006). Female education and maternal mortality: A worldwide survey. Journal of Obstetrics and Gynaecology Canada, 28(11), 983-990.

McTavish, S., Moore, S., Harper, S., \& Lynch, J. (2010). National female literacy, individual socioeconomic status, and maternal healthcare use in sub-Saharan Africa. Social Science and Medicine, 71(11), 1958-1963.

Midhet, F., Becker, S., \& Berendes, H. W. (1998). Contextual determinants of maternal mortality in rural Pakistan. Social Science and Medicine, 46(12), 1587-1598.

Mumtaz, Z., \& Salway, S. M. (2007). Gender, pregnancy and the uptake of antenatal care services in Pakistan. Sociology of Health and Illness, 29(1), 1-26.

Nisar, N., \& White, E. (2003). Factors affecting utilization of antenatal care among reproductive age group women (15-49 years) in an urban squatter settlement of Karachi. Journal of Pakistan Medical Association, 53(2), 47-53.

Sepehri, A., Sarma, S., Simpson, W., \& Moshiri, S. (2008). How important are individual, household and commune characteristics in explaining utilization of maternal health services in Vietnam? Social Science and Medicine, 67(6), 1009-1017. 
Shariff, A., \& Singh, G. (2002). Determinants of maternal healthcare utilization in India: Evidence from a recent household survey (Working Paper No. 85). New Delhi: National Council of Applied Economic Research.

Singh, P. K., Rai, R. K., Alagarajan, M., \& Singh, L. (2012). Determinants of maternity care services utilization among married adolescents in rural India. PLOS ONE, 7(2), e31666.

Thomas, D., Strauss, J., \& Henriques, M.-H. (1991). How does mother's education affect child height? Journal of Human Resources, 26(2), 183-211.

Tura, G., \& Gebremariam, A. (2008). Safe delivery service utilization in Metekel zone, northwest Ethiopia. Ethiopia Journal of Health Sciences, 17(4), 213-222.

Webb, P., \& Block, S. (2003). Nutrition knowledge and parental schooling as inputs to child nutrition in the long and short run (Nutrition Working Paper No. 3). Washington, DC: Development Alternatives, Inc.

Winkvist, A., \& Akhtar, H. Z. (1997). Images of health and healthcare options among low-income women in Punjab, Pakistan. Social Science and Medicine, 45(10), 1483-1491.

Woldemicael, G. (2007). Do women with higher autonomy seek more maternal and child healthcare? Evidence from Ethiopia and Eritrea (Working Paper No. 2007-035). Rostock: Max Planck Institute for Demographic Research.

World Health Organization. (2006). Provision of effective antenatal care: Integrated management of pregnancy and childbirth (IMPAC) (Standards for Maternal and Neonatal Care No. 1.6). Available from

http://www.who.int/reproductivehealth/publications/maternal _perinatal_health/effective_antenatal_care.pdf

World Health Organization. (2013). Data and statistics [Webpage]. Retrieved from http//www.who.int/research/en/ 


\section{Appendix}

\section{Table A1: First-stage regression results of health knowledge (endogenous covariate)}

\begin{tabular}{|c|c|}
\hline Explanatory variables & Coefficient \\
\hline \multicolumn{2}{|l|}{ Instrumental variable } \\
\hline \multicolumn{2}{|l|}{ Mass media exposure } \\
\hline Heard a family planning message on radio or TV in the last month & $\begin{array}{c}0.256^{* * *} \\
(0.051)\end{array}$ \\
\hline \multicolumn{2}{|l|}{ Individual characteristics } \\
\hline \multicolumn{2}{|l|}{ Age (years) } \\
\hline \multicolumn{2}{|l|}{$<25$ (base case) } \\
\hline $25-34$ & $\begin{array}{c}0.054 \\
(0.057)\end{array}$ \\
\hline $35-49$ & $\begin{array}{l}-0.075 \\
(0.81)\end{array}$ \\
\hline \multicolumn{2}{|l|}{ Education } \\
\hline \multicolumn{2}{|l|}{ None or less than primary (base case) } \\
\hline Primary but below middle & $\begin{array}{l}-0.033 \\
(0.081)\end{array}$ \\
\hline Middle but below secondary & $\begin{array}{l}-0.023 \\
(0.090)\end{array}$ \\
\hline Secondary and above & $\begin{array}{c}0.091 \\
(0.080)\end{array}$ \\
\hline Working woman & $\begin{array}{c}0.368^{* * *} \\
(0.059)\end{array}$ \\
\hline $\begin{array}{l}\text { Child's birth order } \\
1 \text { (base case) }\end{array}$ & \\
\hline 2 to 3 & $\begin{array}{l}0.104^{*} \\
(0.060)\end{array}$ \\
\hline 4 to 6 & $\begin{array}{l}0.157^{* *} \\
(0.074)\end{array}$ \\
\hline $7+$ & $\begin{array}{c}0.288^{* * *} \\
(0.097)\end{array}$ \\
\hline Previous fetal loss or stillbirth & $\begin{array}{c}0.319^{* * *} \\
(0.062)\end{array}$ \\
\hline Previous fetal loss or stillbirth * working woman & $\begin{array}{l}-0.194^{*} \\
(0.107)\end{array}$ \\
\hline Planned pregnancy & $\begin{array}{c}-0.171^{* * *} \\
(0.051)\end{array}$ \\
\hline
\end{tabular}


Explanatory variables

Coefficient

Husband's education

None or less than primary (base case)

Primary but below middle

$(0.071)$

Middle but below secondary

$(0.066)$

Secondary and above

$(0.060)$

Husband has skilled employment

$-0.107^{* *}$

Discussed place of delivery with spouse

$0.242^{* * *}$

(0.046)

Husband is a blood relation

$0.080^{*}$

$(0.044)$

Wife of household head

Household characteristics

Household wealth (index)

$-0.053^{*}$

Number of household members

(0.005)

\section{Community characteristics}

Place of residence

Region

Urban (reference)

Rural

Punjab (reference)

Sindh

KP

Constant

Number of observations

4,174

Notes: ${ }^{*} \mathrm{p}<0.10,{ }^{* *} \mathrm{p}<0.05,{ }^{* * *} \mathrm{p}<0.01$.

Robust standard errors at cluster level are given in parentheses below estimates.

Source: Authors' calculations based on PDHS 2006/07 data. 
Table A2: Proportion of working women, by socioeconomic status

\begin{tabular}{lcccc}
\hline & \multicolumn{2}{c}{ Women working } & \multicolumn{2}{c}{ Women not working } \\
\cline { 2 - 5 } Wealth & Number & Percentage & Number & Percentage \\
\hline Low & 338 & 38 & 502 & 17 \\
Medium low & 250 & 25 & 587 & 20 \\
Medium & 247 & 17 & 593 & 20 \\
Medium high & 181 & 12 & 659 & 21 \\
High & 127 & 7 & 709 & 21 \\
\hline
\end{tabular}

Source: Authors' calculations based on PDHS 2006/07 data.

Table A3: Working women, by employment type

\begin{tabular}{lcc}
\hline Employment type & Number & Percentage \\
\hline Skilled work & 609 & 13.62 \\
Unskilled work & 3,862 & 86.38 \\
Total & 4,471 & 100.00 \\
\hline
\end{tabular}

Source: Authors' calculations based on PDHS 2006/07 data. 